\title{
Between antagonism and eros: The feud as couple form and Netflix's GLOW
}

\author{
Broderick D.V. Chow \& Eero Laine \\ Women and Performance, 29:3, published online 23 October 2019
}

The trope of feuding women is often characterized by a slippage between the representational and non-representational worlds, between character and performer. Ruth Wilder and Debbie Eagan, the protagonists of Netflix's popular television program GLOW, are contemporary representatives of a form of antagonistic "coupling" that includes celebrity "beefs" (Cardi B and Nicki Minaj), German drama based on English history (Mary, Queen of Scots and Elizabeth I in Friedrich Schiller's Mary Stuart), classic films (All About Eve, 1950, dir: Darryl F. Zanuck) but which stretches back at least to 18th century theatre (see Nussbaum 2013).

Ruth and Debbie, played by Alison Brie and Betty Gilpin, are both actresses, and best friends. While Debbie has made a regular appearance and apparently a good living as an ingenue in a long running soap opera, Ruth has not had a break and finds herself in an endless cycle of auditions and scene study classes. In the pilot episode of the series, Ruth auditions for a women's wrestling promotion, but is unsuccessful. Immediately following the audition in the wrestling ring, she is confronted by Debbie, after Debbie discovers that Ruth has had an affair with her husband. As the pair physically fight in the ring, the show's director, Sam Sylvia (Marc Maron) sees the possibilities of capitalizing on both Ruth's willingness to fight and on the established feud between the two women. Framed by the peculiar theatricality of the professional wrestling ring, the fight highlights the slippage between the supposedly representational in-ring violence, and the "real" feelings of enmity between the former friends. "Is this real?" another aspiring wrestler asks, watching them fight. "Who the fuck cares," answers another. 
The choice of the feud as the principal narrative device in the first season of GLOW is apt, considering the program's subject matter: the world of professional wrestling. Perhaps more than most other narrative forms, professional wrestling has always relied on feuds-extended conflicts between two wrestlers that serve to set up and bridge individual matches. These plotted feuds are designed to provide narrative hooks for audiences, reasons to be invested in the matches, the characters, and the wrestlers themselves. It is not accidental that Debbie moves from soap operas to professional wrestling, even as the two forms are juxtaposed for laughs. Wrestling is often incorrectly construed as a strictly masculine endeavor, whereas "soap opera constructs woman-centered narratives and identifications;" however, like professional wrestling, "not only do soaps never end, but their beginnings are soon lost sight of" (Kuhn 18). Even absent a clear or memorable beginning, like other serial narrative forms (such as soap opera and comic books), professional wrestling follows the familiar cliffhanger arc: characters are introduced, a conflict is presented, and characters then move quickly to resolve that conflict only to then be presented with the introduction of new characters or a further complication of the plot (tune in next week!). Liz Flahive and Carly Mensch, GLOW's creators and showrunners, demonstrating an insider's understanding of professional wrestling's interplay between wrestler and character, structure the first season of the show around both Ruth and Debbie's non-diegetic feud, and the diegetic feud between their in-ring characters or "gimmicks," Zoya the Destroyer (a Russian redscare stereotype) and the "all-American" Liberty Belle. In this way, then, the primary "couple" of the first season of GLOW is Ruth/Debbie (or Zoya/Liberty Belle). While the inciting incident of the feud is an affair that threatens and then dissolves a heterosexual coupling, the viewer does not mourn the demise of Debbie's marriage, but rather celebrates her ever-greater involvement in an antagonistic coupling with Ruth. The "couple feud," in other words, presents a new 
perspective on coupling itself. It's not that a couple is perfect and then falls apart, but rather that coupling itself is antagonistic.

$G L O W$ 's first season narrative reveals how agon is built into the act of coupling more generally. In the example of Ruth and Debbie, dynamics of power are clearly in play well before the outward and publicly performed moment of conflict and antagonism. Debbie's success as an actor is not necessarily indexed to her talent (part of her role on the soap opera that made her famous involves lying in a hospital bed for months while her character is in a coma). When Debbie wants to stop working and raise her child, she has the luxury of a marriage that supports her in giving up everything that Ruth wants and works for. Ruth and Debbie's friendship is writ through with latent and sometimes explicit conflict, even before both the revelation of the affair between Ruth and Debbie's husband. The wrestling ring then contains the conflict and transforms it into a potential source of value for director Sam. By the final episode, however, Debbie and Ruth's coupling threatens the established structures of power and is leveraged in ways that reshapes the antagonism and their work.

The feud — sustained conflict between two parties — is less a particular moment or series of actions, than a way of reading or viewing relational performances that enables us to see both the antagonistic base of most social situations as well as the productive potential of such antagonism. Following the theme of this special issue on the Couple Form, we argue that feuding is a form of coupling. Further, the feud as a couple form opens important registers of coupleness that resist dominant ideas of both sociality and work.

Critiques of the couple form from feminist and queer theory point to the heteronormative visions of coupling that overlay private and public spheres. Lauren Berlant and Michael Warner write that 
Community is imagined through scenes of intimacy, coupling, and kinship; a historical relation to futurity is restricted to generational narrative and reproduction. A whole field of social relations becomes intelligible as heterosexuality, and this privatised sexual culture bestows on its sexual practices a tacit sense of rightness and normalcy. This sense of rightness - embedded in things and not just sex - is what we call heteronormativity (Berlant and Warner 1998, 554).

The couple as a form thus functions as an essential unit in heteronormative structures and strictures. Yet even as the couple form is apparently both constitutive of and by heteronormativity, the couple form's relation to bondedness, devotion, and monogamy stretches into non-heterosexual and even Platonic couplings. Mimi Schippers argues that "monogamy is the first and largely unquestionable discourse in narratives of relationship normalcy, health, and morality and that the pathologization of non-monogamy and erasure of consensual nonmonogamies situates the monogamous couple as normal, moral, and compulsory" $(2016,12)$. The strength of presumed coupled monogamy, like the many heteronormative formations it supports, radiates through numerous social formations, not only in terms of sex. Monogamy in an expanded sense might simply be taken to mean a form of control and marker of power relations within any sort of coupling. Within heteronormativity, relations outside of monogamy are negatively framed as infidelity. However, Schippers argues that the languages and practice of polyamorous or non-dyadic relationship building might invert our common and regressive understandings of jealousy (16-17). As the much-paraphrased story from Jacques Lacan goes: even if the jealous husband's wife is cheating on him, his jealousy is still a pathology (Lacan 1981[1993], 76). The strength of such a pathology is evident even outside the romantic couple, for example, in coupled relations including employer/employee and advisor/advisee. When such couplings become destructive we often read them through the lens of the failed romantic or 
sexual bond; perhaps they are actually more legible through the mutually constitutive form of the feud.

The constitutive antagonism of the couple form has led, as in Schippers's work, to challenging the binary couple by affirming an expansive or poly, "and-and-and" mode of relationality. In this article we are less interested in dissolving the couple, than in putting pressure on the logic of its formation through the notion of the feud. In examining the feud as couple form, this article opens inquiries into the internal contradictions and possibilities of a formation imbued with fraught relations and normative expectations. The couple-feud then acts as a critical lens to examine our social attachments.

The article proceeds chronologically, exploring the political economy of the pre-modern form of the blood-feud and its late modern presence in popular culture. We rehearse the idea of the feud as it emerges from anthropology and philosophy, especially as it impacts notions of debt and alternative economies, before thinking through the late-modern "coupling" of the feud in popular culture, fandom, and television.

\section{Genealogy of the feud}

The word "feud" has multiple and sometimes incompatible valances. A feud is defined as "active hatred or enmity, hostility, ill-will," "a state of bitter and lasting mutual hostility," and "a state of perpetual hostility between two families, tribes, or individuals, marked by murderous assaults in revenge for some previous insult or injury" $(O E D)$. As social phenomena, feuds are very serious, such as the terrifying cycles of revenge violence in the Balkan states of Albania and Montenegro. However, in contemporary English, "feud" has also come to ironically signify a petty or inconsequential disagreement, such as a heated Twitter exchange between pop stars, a storyline in pro wrestling, or the arguments of disgruntled ex-lovers. A genealogy of the concept 
of the feud--from pre-modern social phenomenon to its representation as couple form in popular cultural performances that are often dismissed as "low-brow," feminine, queer, or camp-suggests that the fascination with feuds represents an alternative and older way to value the human outside of the heteronormative, patriarchal, and restricted capitalist economy of abstract and alienated labor. If, for Marx, communism was a spectre of something to come, the feud arises from the ancient past to haunt modernity.

Feuds, vendettas, faide, and clan wars are supposedly incompatible with modernity. The word "feud" emerges in the 17 th century to describe a phenomenon supposedly already purged from the Early Modern Western world. Samuel Purchas's Purchas his pilgrimage: or Relations of the world and the religions observed in all ages and places discovered, from the creation unto this present, describes "Mutuall feuds and battels betwixt their seuerall Tribes and kindreds" (1613, vi. xi. 525) in Africa. Feuding can be seen as a pre-modern step towards the invention of modern instruments of law. In Aeschylus's Oresteia, the reprisals of violence by the House of Atreus are finally settled by the imposition of the rule of law by the goddess Athena. The feud is thus often marked as an atavistic and aberrant ancient phenomenon, across a number of periods. In both Shakespeare's Romeo and Juliet and Gaetano Donizetti's nineteenth century opera Lucia di Lammermoor (based on Sir Walter Scott's 1819 The Bride of Lammermoor), the ancient feud between families prevents the formation of a couple leading to tragic conclusions.

While feuds are considered pre-modern, feuding is actually a complex form of social organization. In his 1940 study of the Nuer people of the Nile Valley, E.E. Evans-Pritchard describes a society where violent feuds and mutual hostility is common: "as Nuer are very prone to fighting, people are frequently killed" (Evans-Pritchard 1940, 151). The violence of blood feuds, however, produces complex political agreements. In the highly granular system he depicts, 
a blood feud may be settled when the "slayer" seeks asylum with the chief, who will, after a few weeks, hold negotiations with the kin of the deceased for a payment of "blood-cattle" in exchange for the life $(1940,153)$. In short, an antagonism inaugurates a redressive legal mechanism, which places exchange value on a human life. Furthermore, feuding drives a system of $d e b t$, as it is unlikely the total amount of cattle will be paid at once. This is similar to other forms of "blood-money" around the world, such as the Germanic wergeld (bloodwealth), or the use of wampum as the medium of Haudenosaunee (Iroquois) peace-making (Graeber 2001, 124$5)$.

In his book Debt: The First 5000 Years, the anthropologist David Graeber demonstrates how these early forms of "social currency" arise from "human economies" of marriage and blood-feud, or in Graeber's terms, games with sex and death $(2011,158)$. However, what might seem like a cold and rational calculus of money for a life is, in Graeber's reading, actually the opposite. Money is, he writes:

first and foremost an acknowledgment that one owes something much more valuable than money [...] At best those paying bloodwealth, by admitting the existence of the debt and insisting that they wish they could pay it, even though they know this is impossible, can allow the matter to be placed permanently on hold (Graeber 2001, 134-5).

In other words, the monetary debt accrued for the taking of life suggests that each person is ultimately invaluable, because they exist uniquely in their relations to others.

However, in a capitalist economy the abstractive and alienating properties of money dissolve the unique value of the human. Despite modern capitalism's insistence on the sanctity of the individual, capitalist labor economy is predicated on the basic fungibility of humans. As Marx noted in Volume 1 of Capital, abstract labour requires one worker to be interchangeable for another. Thus, in a capitalist system, the value of the human is premised on the exchange of their 
labor power to the capitalist for a wage, whereas the premodern feud is part of a human economy that asserts what we might call, following Walter Benjamin, the "auratic" value of the human being $(1969,221-223)$. A feud demonstrates this value of the human (paradoxically) through their potential destruction. We argue, then, that modern capitalist society therefore rejects feuds not necessarily because they are a violent, barbaric remnant of the past, but because they represent another regime of value.

Ontologically, the feud can only be grasped relationally, since the appearance of actual definitive hostility or violence, or the institution of a redressive or juridical mechanism, is that which potentially ends the feud. In other words, the feud produces a kind of queer kinship, binding subjects and groups together in a relation that circumvents or supplements traditional kinship. Here, we might look to the anthropological notion of the gift, which similarly suggests another order of value and kinship as gifts are given, but only in a political economy of status and rivalry. Paradoxically, some gift economies, such as the potlatch form of the Coast Salish First Nations, are based in conflict or feuding. This form of symbolic exchange (i.e. not rooted in a profit making or necessarily based on labor) creates an economy of loss wherein one gives something up or destroys it in front of another, who is then compelled to give something else up or destroy something even more valuable in order to attain or retain social standing. Marcel Mauss notes in The Gift that in many civilizations "exchanges and contracts take place in the form of presents; in theory these are voluntary, in reality they are given and reciprocated obligatorily" (1990 [1954] 1). Mauss goes on to describe civilisations where it is notable that "the principle of rivalry and hostility that prevails in all these practices" (8). Such rivalry manifests in the apparently act of destroying individual wealth and valuable resources in order to outdo or outspend a rival and in many occasions redistributing property throughout a community. 
This expenditure is not taken up out of kindness but from a wholly antagonistic perspective - as Christopher Bracken writes, "the potlatch is a war fought with property" $(1997,66)$. As a feud, the potlatch economy is similarly incompatible with bourgeois capitalism, hence, its banning by the Canadian federal government between 1884 and 1951. For the philosopher Georges Bataille, the transition to industrial capitalism required the bourgeoisie to conceal its expenditure, to spend only for itself $(1985,124-5)$. The presence of wasteful economies - based in loss of goods or life —is anathema to the closed or "restricted" (Bataille 1985) economy of industrial capitalism, which tries to stave off its eventual demise in entropy.

In this way, feuding differs from competition; its value, as in the gift economy, is predicated on waste and destruction, as opposed to accumulation and production. We can therefore discern an abstract principle about the feud: it resists the thermodynamic model of the restricted industrial capitalist economy, which aims at competitive equilibrium. For the feud, arrival at equilibrium would bring about the end of the feud. We suggest then that the feud might be read as a spectre of what Georges Bataille called the general economy that is haunting the present, often in popular, feminized, and queer forms.

\section{The feud as couple form}

Across a number of media, but especially in serialized entertainments, feuds play out as a fundamental bind of antagonism and eros that make them particularly useful to examine as forms of coupling. In its transition from a pre-capitalist social formation to a cultural trope, feuding between families, clans, and tribes has been largely replaced by feuding between individuals, a domesticated version of the ancient antagonism. Whereas pre-20th century feud narratives might have focused on the tragedy of the couple torn apart by a inter-clan feud, the individualized feud can be seen as a couple in its own right, encompassing hate-love dynamics such as Wicked's 
Elphaba and Galinda. Musical-theatre scholar Stacy Wolf reads the characters' Act One feud as part of a larger queering of the structure of the "integrated musical", reading the musical as a queer and feminist romance $(2008,1)$. However, while in the ur-text of Frank L. Baum's The Wizard of $O z$, the enmity between the witches is permanent and irresolvable, by Act Two of Wicked the feud is over and the protagonists have been reconciled.

Another feature of the feud in contemporary popular culture is its tendency to blur the boundaries between the diegetic and non-diegetic worlds of the artwork. Take, for instance, one of US cinema's best known feuding couples, Ted and Joanna Kramer in Robert Benton's Kramer vs. Kramer, played by Dustin Hoffman and Meryl Streep. Rumors of an off-screen feud between the actors have long accompanied this story of a divorce and prolonged custody battle, with one particular scene in which Hoffman slaps Streep being read as unscripted and "real" (Daily Telegraph, 2017). When Janet McTeer and Harriet Walter appeared in Schiller's Mary Stuart in London's West End, many spectators assumed they hated each other offstage. Joan Crawford and Bette Davis's well-known off-screen feud during What Ever Happened to Baby Jane? has become the subject of Ryan Murphy's television show Feud. Furthermore, audiences demonstrate enormous investment in the "real-life" feuds of celebrity personalities; the social media wars between "stans" of popstars Katy Perry and Taylor Swift is perhaps a sort of late capitalist manifestation of the 19th century actor feuds like the one leading up to the Astor Place Riot (1849), which involved a dispute between actors Edwin Forrest and William Charles Macready and their fans. Especially in popular entertainments, in straddling the diegetic and non-diegetic worlds of the artwork, a feud is often a marker of a queer porosity between signifier and signified, representation and materiality. 
The popular appetite for feuding couples has existed at least since the eighteenth century. Felicity Nussbaum suggests that "Rival Queens," i.e. feuding actresses, were regularly the stars and main theatrical attractions during this period. Feuding arose from a competitive economy in which actresses were "rivals to each other, as well as to managers and other actors, and also to prevailing ideas about women.” $(2010,26)$. This accounts for the large number of plays from the period that feature rival or feuding women characters, as off-stage feuds produced onstage feuds and vice versa, with diegetic and non-diegetic coupling-feuding participated in an ongoing economy of attention $(2010,66)$. But at stake in these diegetic and non-diegetic rivalries is the body itself, as in an incident Nussbaum describes of a fake stabbing escalating to a real stabbing onstage during a fight scene. She writes, "the incident reveals the way that actresses' bleeding bodies and their affairs of the heart carry a personality onto the stage that traverses the stage's edge and, through its attachment to female bodies, far exceeds that of the actors" $(2010,80)$.

What Nussbaum's study of 18th century theatre reveals for the modern couple feud is the way in which the primitive antagonism of the feud continues to resist the substitution of one person for another. In the realm of the theatre, a representational space that epitomizes human fungibility because a single character can be embodied by many actors over time, the way that "the women players are perceived simultaneously to be both the dramatic characters and themselves, and any theatrical action is rife with personal meanings" again suggests another form of value for the human outside of abstract labour (Nussbaum 2010, 80). A feud between celebrity actresses creates value not because of their ability to substitute for another, to play a role, in other words, but because a real-life feud could potentially result in the death or retirement of one of the actresses involved. Nussbaum's feminist historiographical critique potentially explains 
why modern celebrity feuds tend to be gendered as feminine, with participants marked as "difficult" or "diva-ish."

Since the 18th century's celebrity rivalries, there has been a tendency to "couple" the feud, which is still determinant of contemporary feuds. The couple-feud marks a pairing that loiters in enmity. It does not only defer its resolution in violent conflict out of fear of destroying one or both parties, but for fear of destroying the couple itself. The couple-feud desires to remain in antagonism, because the other side of the antagonism is surely eros, which is made explicit in the fandom practices of slash fiction and of "shipping" rivals and antagonists across genres. As Taylor Boulware argues, when fans "ship" characters, they "refuse normalizing generic contrivances, and reject closed textual borders and the capitalist, sexist, and heteronormative ideologies those contrivances enact and reproduce" (Boulware 2017, 34). The practice of "lovehate" shipping in popular culture therefore demonstrates the queer and subcultural nature of the feud's persistence in late capitalism. What began as a patriarchal practice that facilitated the exchange of money and women, in the present day persists in "low culture," serialized, and feminized forms embraced by a popular fan base.

Serialized forms such as comic books, sitcoms, and soap opera enable a representation of the feud-couple that avoids closure or resolution, sometimes for decades at a time. That sense of time is important, as the ongoing everydayness of television was not always recognized by the academy as worthy of study. As Michele Hilmes reminds us in "the Bad Object: Television in the American Academy": "Feminists fought hard to put television on the film studies agenda. Work on soap operas, domestic sitcoms, and female-centered drama formed a crucial part of early television studies" (113). While it may be tempting to think of Netflix seasons as very long movies because one can sit down and binge the whole thing at once, the shows are still broken 
into episodes that leads from the last into the next. The televisual narrative structures our interactions and allows us to stop, go away, and come back--breaking up the mundane of our lives even as the show itself bleeds into the day-to-day of our lives. Kathryn VanArendonk argues for considering and maintaining the episode as the unit by which to measure televisual narratives: “An episode can stand by itself but cannot exist alone; it is a unit defined by its content as well as its organizing frames; it is a form that produces objects that can appear both formulaically identical and entirely dissimilar" (68). The episode thus shapes the way we view and the way we think of the interactions between characters. Especially in streaming television, which is often viewed on handheld devices that encourage us to touch and to hold such images close and in intimate places, in bed for instance, we encounter these characters closely. We watch them sometimes secretly, according to their time, we imagine them privately.

Similarly serialized and handheld, albeit print-bound, the coupling of the superhero and supervillain in comic books encourages the imagining of an antagonistic pairing in which one is always constitutive of the other. These are often spoken of in the same breath: Wolverine and Sabretooth; Professor X and Magneto; Batman and Joker. Across storylines and years of publications and running in parallel to the comic book's approved and usually heterosexual couple, the superhero/supervillain coupling provides a homosocial or even queer layer to a heteronormative form. Resolution of the feud cannot be permitted by the comic book's serialized form, since such resolution would end the narrative, even as romances come and go. Televised genres, such as soap opera and sitcom function in a similar way, with coupled rivalries providing the basis for dramatic tension or laughter.

Within the serial, then, the feud is productive in a speculative way, a fictional labor that continually projects forwards towards its eventual, but always deferred, realization as value, in 
the destruction of one party of the feud. In this way, the couple-feud is a darker version of what Giulia Palladini calls foreplay, a form of labour in performance that looks towards its realization as an event, but which lingers in the pleasure of its unproductivity. "The mode of production I call foreplay", she writes,

is figured as a counterforce within productive economy, as a prelude where value is not yet conferred upon labor. I observe this force in relation to its potential valorization, not only in terms of productive value [...] but also in an alternative economy enacted in the present (Palladini 2017, 21).

However, like the amateur labor of foreplay that Palladini marks as prefiguring the conditions of the precarious worker in the present day culture industry, the alternative economy of the feud does not easily resist its conversion into surplus value. In fact, the domesticated, defanged feuds of contemporary popular culture parallel the pervasive neoliberal idea of competition as goal, demonstrating how conflict itself may be leveraged for profit.

We can also perceive in these examples the couple-feud's somewhat ambiguous relationship to late capitalism. The popularity of representations of the feud today demonstrate late capitalism's ability to transform conflict into profit, doing so by domesticating the feud as feminized, queer, or camp. At the same time, the couple-feud threatens this capacity, since its queer form suggests forms of relation and coupling that reject both the reproductive-labor of heterosexual kinship, but also social reproduction, those forms of affective, gendered labor that enable the smooth functioning of capitalism. We now turn back to Netflix's $G L O W$ to examine the domestication of the feud and its disruptive potential through a performance form almost entirely constituted by affective acts of socially reproductive labor: professional wrestling.

\section{Wrestling Couples}


If, as Alisa Solomon suggests in her introduction to The Queerest Art, it is the human body onstage "in all its sweating, spitting specificity" $(2002,9)$ that is theatre's sustained and imminent threat to established the social order, then professional wrestling just might be the premier art of the revolution. We write this with some irony, of course, given professional wrestling's long and troubling history of regressive, masculinist politics, however, theatre and performance and wreslting scholars have long understood the latent possibilities for professional wrestling, if not as necessarily revolutionary, but certainly as progressive, as feminist, and as queer. (See for instance: Aiba 2011, 2017, and 2018; Bradbury 2017; Catte and Howard 2018; Chow 2014; Dunn 2017; Ferguson 2019; Greer 2017; Harkulich 2018; Haynes 2013, 2015 , 2016; Laine 2018; Levi 2008 and 2017; Mazer 1998; Rahilly 2005; Rizzo 2017; Salmon and Clerc 2005; Vega Guinea 2018; Warden 2018; Wood and Litherland 2017.) As a theatrical form that demands the knowing complicity of its audience (the audience must not only suspend disbelief, but loudly perform their suspension of disbelief), one of professional wrestling's most subversive formal features is its ability to explore ideas of labor, work, and the body's fragile role in this social structure. In wrestling's visible and highly embodied labor politics, the insurgent possibilities of the couple-feud come to the fore.

As a serial, narrative form that often apes sports in structure and style, professional wrestling history is tracked through championships (i.e. who holds the title belt) and through feuds, which are the storylines and grudges held between two or more wrestlers. While in most sports, the reason to compete is often as simple as one competitor wanting to prove themselves better than the other, in wrestling, the motivation is often quite personal. Feuds keep audiences interested in following a serial form. In an era in which even independent, grassroots promotions are sustained through internet streaming subscriptions and season tickets, the feud as narrative 
device is crucial to the wrestling business model. Thus, wrestling is the performance form that best demonstrates the all-encompassing ability of capitalism to transform conflict into profit. At the same time, wrestling's paradoxically theatrical form holds the possibility of subverting this tendency, and short circuiting the appropriation of the feud.

Promoters must walk a fine line: in order to maintain audience investment and attention, the feud must promise resolution in the narrative downfall of one or both opponents; but such a resolution would effectively end this mode of production. Yet, as an embodied theatrical form whose core content is the simulation of violent action, the promoter must also give intermittent bursts of violent conflict to maintain the feud, or even mark its existence. Like a glass factory that will literally freeze up if the furnaces are not constantly fueled, the wrestling feud is a precarious mode of production in the midst of a theatrical form, constantly threatening its own profit motive. Fans often report that seeing a long-awaited match between rivals is actually anticlimactic, in the same way that when television writers perform fan service and allow a longstanding couple-feud to hook-up, the sex is disappointing. Both are examples of a kind of "theatrical disappointment" in the disjuncture between expectation and event that Nick Ridout argues is constitutive of the Modern theatre and its embeddedness in capitalist economies of labour and leisure (Ridout 2006, 3).

At the same time, like other feuds in popular culture, audiences invest in the couple-feud, threatening the authority of the creator of the property, in this case, the promoter. Wrestling adds to this audience-led economy, the knowing and often winking participation of the performers, for fans are invested in the wrestlers both as characters and as wrestlers/workers (Chow and Laine 2014). In other words, the diegetic slippage of the feud, in which fans imagine a backstage erosin-antagonism, is often played into by the wrestlers themselves. In this way, the collaborative 
nature of wrestling means that antagonism can be openly read as eros, either real or imagined. Indeed, some famous feuds in professional wrestling have consisted of two people who were actually very dear friends. For instance, Broderick Chow and Eero Laine write about wrestlers JBL and Eddie Guerrero, whose various feuds have included personal and political insults that have involved family members and threats of deportation, and have escalated physically into what is still considered one of the bloodiest matches in recent professional wrestling history (Chow and Laine 2014).

Indeed, it seems that in some ways those feuds that are based in friendship or a deep sense of care can be the most bloody. Mick Foley and Terry Funk performed in matches that were absurd in their violence, involving barbed wire, thumb tacks, metal chairs, fire, and small explosive devices. Foley writes about his matches in Japan and on the US independent circuit with Funk and others and describes receiving an astoundingly low fee for his work, even as promoters clearly benefited from his blood-soaked labor (Foley 2000). Indeed, there is a seeming direct connection between such hardcore wrestling and the vampiric quality of capitalism described by Marx: the promoters literally extract the blood of the laborers for profit. (Chow and Laine 2014). Here the promoters leverage the friendship, the excess labor put in perhaps out of love for one's partner to turn more profit. Yet, at the same time, the bloodiness of these matches demonstrate a form of value in excess of the production of surplus value. When Eddie Guerrero blades and bleeds all over the ring for close to fifteen minutes and is helped by his friend and feuding opponent, there is kind of affective surplus that supersedes the economy of promoterevent-audience. This is an example of the potential disruptive nature of the feud to capitalist production and sociality, its return to premodern regimes of value. Like Guerrero and JBL, or 
Foley and Funk, the central couple-feud of the first season of GLOW demonstrates a potential subversion of the theatrical economy of wrestling.

GLOW, or Gorgeous Ladies of Wrestling, was the first televised all women's professional wrestling company founded in 1985 and airing for five seasons following its premier in 1986. It featured an eclectic cast of performers and characters based on various stereotypes, cultural touchstones, and archetypes. The 2017 Netflix series of the same title, a fictionalized version of the making of the company, was devised by showrunners Flahive and Mensch after watching a 2012 documentary on the original promotion.

Whereas the second season is properly episodic and highlights a number of the secondary and tertiary characters, the first season of $G L O W$ is a fairly linear narrative about the struggle to get the television show made. (The third season has been announced but is unaired as of this writing.) Over the course of the first season, the director, Sam (Marc Maron) and producer Bash (Chris Lowell) gain and lose funding, secure a venue, and hire a complete cast of women wrestlers. The feud between Ruth and Debbie persists throughout the season as the central conflict, both driving and providing obstacles for the plot. In this way, GLOW's narrative is not dissimilar to other workplace sitcoms, many of which also feature long-standing feuds that stretch across multiple seasons, such as The Office's Jim and Dwight. But GLOW's specific professional wrestling context enables an illustration of the subversive economic logic of the feud: the way the feud's pre-modern auratic valorization of the human threatens the productivity of the capitalist/promoter.

For the promoter, Sam, Ruth and Debbie's value as workers is tied to their "real-life" feud - in other words, for Sam, it is their actual antagonistic feelings for each other that drives their ability to sell the match. In his belief, Sam fundamentally misunderstands the professional 
wrestling form, which rather uniquely straddles and slides between theatricality and performance (Chow, Laine, and Warden 2017). As a theatrical form, wrestling's violent actions are actually a manifestation of cooperation, trust, and care (Levi 2008, 36; Smith 2008; Chow 2014, 79), though crucially, such embodied acts of love can take place in the absence of feelings of love, or even liking (Warden, Chow and Laine 2018, 208). Ruth and Debbie's training montage in episode seven of the first season and their subsequent build up to the big match illustrate how they, as wrestlers, work together in the ring but continue to hold the grudge that gained them each their role. Though fictional, the show's narrative accurately represents the multiple "real life" grudges that appear throughout the history of wrestling, including many iconic pairings, such as Hulk Hogan and the Ultimate Warrior (The Sportster, 2017). By eliding antagonistic feelings and fake violence, Sam misrecognizes the threat to his power that the feud represents.

In various episodes throughout the first season, Sam attempts to control the erratic labor of the performers through training, as well as other tools such as curfews and assigned housing. Such actions were reported by the original GLOW wrestlers in the 2012 documentary GLOW: The Story of the Gorgeous Ladies of Wrestling (dir. Brett Whitcomb). The former wrestlers describe regulations on parties and prohibitions on which wrestlers could meet or be seen publicly with other. At the time, this was practiced by many wrestling promoters as they tried to maintain the illusion that both the feuds and the matches were real (it made no narrative sense to have wrestlers who supposedly hated each other buying each other rounds at the bar after the show or carpooling to their cage match). These social controls suggest a real danger for the promoter coming from the wrestlers. From the perspective of the promoter, the wrestlers are commodities--congealed labor themselves--that must be protected from themselves and each 
other, and as an added danger, there is the possibility that the wrestlers might somehow emperil the source of value, the narrative feud.

Although Sam attempts to control and supervise the workers outside of rehearsal, in the final episode Debbie and Ruth conspire to shift the narrative of the production by leveraging their personal conflicts. They do this by employing one of the oldest performance devices in professional wrestling, the "work." Derived from the carnival slang "working" a "mark", i.e. deceiving a naive person, a "work" in wrestling is a deception, often collaborative in nature. Most frequently, the work is maintaining the diegetic world of the wrestling narrative, often referred to as "kayfabe." As deployed by wrestlers and promoters, the marks are usually the audiences who get worked into believing what they see as real, but wrestlers can also work each other and, indeed, they can work a promoter.

Shortly before the big show, Debbie apparently abandons the production without warning and Ruth's match is rebooked. All of the wrestlers and Sam believe that Debbie has quit, leaving the show in difficult position without its hero and lead actor. The show goes on, however, and Ruth, as Zoya, is put in a tag team match, which she wins with Jenny "Fortune Cookie" Chey (Ellen Wong). Zoya, a deceitful Cold War Russian gimmick, then promptly double crosses her partner. Just as she is about to be crowned the champion, Debbie, as Liberty Belle, stands up in the crowd and challenges Zoya to a match. Debbie's appearance as Liberty Belle is a surprise to the audience, the wrestlers, and to Sam, who has now lost narrative control of his entertainment product. Debbie and Ruth wrestle their match, which features a number of moves and callbacks to their training session montage as if to show that their shared physical labor both feeds and cuts through their interpersonal feud, while allowing them control over their in-ring wrestling feud. What started the season as a real fight has been honed and tempered through their sweaty work 
as a tool against their boss. The feud has become excessive to the diegetic realm of the ring that is tightly controlled by Sam, the director.

Liberty Belle wins the match and is crowned the champion. However, almost immediately, Sam sends another wrestler rush to the ring and steal the crown: wrestler Tammé Dawson (played by Kia Stevens), who portrays the wrestler Welfare Queen, a racist, anti-black, 1980s stereotype. Dawson's interference in the match at the bequest of Sam does not allow for a clean resolution to the narrative, but rather opens the possibility for a further feud, now between Debbie's and Dawson's characters.

Debbie's challenge from the stands is notable because it was not sanctioned or planned by the promoter. It opens an ambiguity to the otherwise predetermined and productive narrative. What if the challenge is real and Debbie plans to fight Ruth and disrupt the theatrical frame of the wrestling match? What if the performers have conspired to rewrite their characters or the plot, essentially taking taking back creative control? Even as the last minute challenge might be profitable for the promoter as an exciting plot twist, it cannot stand from the perspective of the promoter's desire to control the labor of the wrestlers. The couple-feud has become dangerous to Sam's authority and the continuation of the storyline feud. Sam's intervention in the feud-in order to build another feud - disrupts any plans Debbie and Ruth may have had outside of Sam's authority, and the fact that his intervention is staged with a sensationally racist character, plays on the worst populist impulses of the audience. The feud in the narrative of the show is dangerous to Sam's production as it both facilitates Ruth's and Debbie's interpolation into what was initially humiliating work and possibly short circuits the typical mechanisms of capitalist control. By fully taking on their characters, perhaps becoming their characters, they are able to write their own narratives. 


\section{Conclusion}

In Glamour magazine, Betty Gilpin (2017) describes the feeling of physical empowerment that came from learning to wrestle. She describes the way becoming strong enough to lift her partner-opponent kicked back against her long-standing desire to "skip thinking about [her] body as an existing thing altogether." She notes the peculiar pleasure of pretending to fight: "The 14 of us put our faces in each other's armpits and crotches, grabbing the meat of each other's stomachs and thighs as we scream-danced each other to the ground. My body was listening, talking. To her body, to her body, to her body." In (half)imaginary acts of pain ("I slammed to the ground"), there is pleasure: "For the first time in my life I could feel my whole body listening. Go here. Come here. Be still. Take charge. Now one, two, three, fly." Professional wrestling, as portrayed in $G L O W$, becomes a site where feuds are physicalized, where the couple form is bound relationally and in the flesh.

When bodies come together, in couples or otherwise, there is invariably friction. Friction is ambivalent. It is a source of pleasure, the touch that slips over the edge into the ecstatic. Yet just as easily friction becomes irritation—nagging, abrading, the wearing away of one's edges. Friction is how we confront the boundaries of ourselves. It is a messy affect that indicates how we don't go together, how at the heart of every coupling is a constitutive antagonism that is also productive of eros. Feuds, of course, are frictional. But as we have attempted to demonstrate, such antagonistic couplings can be pleasurable, if not erotic then something approaching it. What $G L O W$, and professional wrestling more generally, illustrate is that the erotic does not need to be accompanied with other positive or warm feelings such as love or even "liking." Rather, one can feel the erotic even in the antagonistic form of the feud. 
For the promoter, there is the persistent threat that the diegetic feud could become a real feud, disrupting business and storyline due to injuries, lawsuits, etc., but also that the feud might actually be a cover for eros, the potential for coupling and therefore, working together. Then the danger is that the feud between two workers might change into a feud between workers and capitalist. Eros, in this sense, might be considered in terms of workers' associations or as the basic cooperation of two wrestlers to "work" the promoter. The threat of the feud, then, is not the threat of violence, which one way or another would result in the feud's resolution, it is the threat of its coupling - that antagonism is actually eros, or that eros was hidden in plain sight all along as antagonism. In the context of late capitalism's ability to turn even conflict to profit, the couple-feud's threat is one of stasis, even entropy. It threatens to shut down the perpetual motion value extraction of post-industrial capitalism, by lingering in the pleasure of the fight. Existing in the liminal space between antagonism and eros, the feud is the wilder cousin of friendship, producing value even as it threatens production.

\section{WORKS CITED}

Aiba, Kiko. 2011. Japanese women professional wrestlers and body image. In Transforming Japan: How feminism and diversity are making a difference, edited by Kumiko FujimuraFanselow, 268-283. New York: The Feminist Press.

Aiba, Kiko. 2017. The impact of women's pro wrestling performances on the transformation of gender, translated by Minata Hara. In Performance and professional wrestling, edited by Broderick Chow, Eero Laine, and Claire Warden, 85-94. London and New York: Routledge.

Aiba, Kiko. 2018. Transformed bodies and gender norms: Gender identity of Japanese women pro wrestlers. In Identity in professional wrestling: Essays on nationality, race, and gender, 120136. Jefferson, NC: McFarland \& Company.

Bradbury, Janine. 2017. Grappling and ga(y)zing: Gender, sexuality, and performance in the WWE debuts of Goldust and Marlena. In Performance and professional wrestling, edited by Broderick Chow, Eero Laine, and Claire Warden, 107-117. London and New York: Routledge. 
Benjamin, Walter. 1969. Illuminations: Essays and Reflections, edited by Hannah Arendt, translated by Harry Zohn. New York: Schoken Books.

Berlant, Lauren and Michael Warner. 1998. Sex in public. Critical inquiry 24, no. 2 (Winter): 547-566.

Boulware, Taylor. 2017. Fascination/Frustration: Slash fandom, genre, and queer uptake. PhD Diss., University of Washington.

Catte, Elizabeth and Josh Howard. 2018. "A secret fascination": Professional wrestling, gender non-conformity, and masculinity. In Identity in professional wrestling: Essays on nationality, race, and gender, 137-147. Jefferson, NC: McFarland \& Company.

Chow, Broderick. 2014. Work and shoot: Professional wrestling and embodied politics. TDR: The drama review 58, no. 2 (T222): 72-86.

Chow, Broderick and Eero Laine. 2014. Audience affirmation and the labour of professional wrestling. Performance research 19, no. 2 (June): 44-53.

Chow, Broderick, Eero Laine, and Claire Warden. 2017. Introduction: Hamlet doesn't blade: Professional wrestling, theatre, and performance. In Performance and professional wrestling, edited by Broderick Chow, Eero Laine, and Claire Warden, 1-6. London and New York: Routledge.

Dunn, Carrie. 2017. "Most women train with mostly men, so why not wrestle them?:" The performance and experience of intergender professional wrestling in Britain. In Performance and professional wrestling, edited by Broderick Chow, Eero Laine, and Claire Warden, 95-104.

London and New York: Routledge.

Evans-Pritchard, E. E. 1940. The Nuer. Oxford, UK: Clarenden Press.

Foley, Mick. 2000. Have a nice day: A tale of blood and sweatsocks. New York: Harper Entertainment.

Furguson, LaToya. 2019. An encyclopedia of women's wrestling: 100 profiles of the strongest in the sport. New York: Sterling Publishers.

GLOW: The story of the gorgeous ladies of wrestling. Directed by Brett Whitcomb. Los Angeles: Connell Creations and Window Pictures, 2012

Graeber, David. 2001. Towards an anthropological theory of value: The false coin of our own dreams. New York: Palgrave Macmillan.

Graeber, David. 2011. Debt: The first 5000 years. New York: Melville House Publishing. 
Greer, Stephen. 2017. "King of the ring and queen of it too:" The exotic masculinity of Adriene Street. In Performance and professional wrestling, edited by Broderick Chow, Eero Laine, and Claire Warden, 118-126. London and New York: Routledge.

Harkulich, Christiana Molldrem. 2018. Sasha Banks, the boss of NXT: Media, gender, and the evolution of women's wrestling in WWE. In Identity in professional wrestling: Essays on nationality, race, and gender, 148-161. Jefferson, NC: McFarland \& Company.

Haynes, Nell. 2013. Global cholas: Reworking tradition and modernity in Bolivian lucha libre. The journal of latin american and caribbean anthropology 18, no. 3 (November): 432-446.

Haynes, Nell. 2015. UnBoliviable bouts: Gender and essentialisation of Bolivia's cholitas luchadoras. In Global perspectives on women in combat sports: Women warriors around the world, edited by Christopher R. Matthews and Alex Channon, 267-283. London: Palgrave MacMillan.

Haynes, Nell. 2016. Kiss with a fist. Journal of language and sexuality 5, no. 2: 250-275.

Herman, Allison. 2018. "I can't even tell you how much fun it was": Talking to 'GLOW' breakout Kia Stevens. The Ringer. July 3. https://www.theringer.com/tv/2018/7/3/17527216/kiastevens-glow-season-two.

Hilmes, Michele. 2005. The Bad Object: Television in the American Academy. Cinema Journal 45, no. 1: 111-116.

Ian, Gentleman. 2017. “Top 20 cases Of real life hatred In WWE.” The Sportster. July 5. https://www.thesportster.com/wrestling/top-20-cases-of-real-life-hatred-in-wwe-history/.

Kuhn, Annette. 1984. Women's genres: Melodrama, soap opera, and theory. Screen 25, no. 1: $18-28$.

Lacan, Jacques. 1981[1993]. The Seminar of Jacques Lacan, Book III: The Psychoses, 19551956. Trans. Griggs, Russell. New York and London: W.W. Norton \& Company.

Laine, Eero. 2018. Professional wrestling scholarship: Legitimacy and kayfabe. The popular culture studies Journal 6, no. 1: 82-99.

Levi, Heather. 2008. The world of lucha libre: Secrets, revelations, and Mexican national identity. Durham, NC: Duke University Press.

Levi, Heather. 2017. Don't leave us in the hands of criminals: The contested cultural politics of lucha libre. In Performance and professional wrestling, edited by Broderick Chow, Eero Laine, and Claire Warden, 59-69. London and New York: Routledge.

Lorde, Audre. 1984. Uses of the erotic: The erotic as power. In Sister outsider: Essays and speeches, 53-59. Freedom, CA: Crossing Press. 
Marx, Karl. 2010. Capital: Volume I: A critique of political economy. New York: Penguin Books.

Mazer, Sharon. 1998. Professional wrestling: Sport and spectacle. Jackson, MS: University Press of Mississippi.

Nussbaum, Felicity. 2013. Rival queens: Actresses, performance, and the eighteenth-century British theater. Philadelphia: University of Pennsylvania Press.

Palladini, Giulia. 2017. The scene of foreplay: Theater, labor, and leisure in 1960s New York. Evanston, IL: Northwestern University Press.

Purchas, Samuel. 1614. Purchas his pilgrimage: or Relations of the world and the religions observed in all ages and places discovered, from the creation unto this present. Boston Public Library. https://archive.org/details/purchashispilgri00purc/page/n0.

Rahilly, Lucia. 2005. Is RAW war? Professional wrestling as popular S/M narrative. In Steel chair to the head: The pleasure and pain of professional wrestling, 213-231. Durham, NC: Duke University Press.

Ridout, Nicholas. 2006. Stage fright, animals, and other theatrical problems. Cambridge, UK: Cambridge University Press.

Rizzo, Laura Katz. 2017. "Gold-dust": Ricki Starr's ironic performances of the queer commodity in popular entertainment. In Performance and professional wrestling, edited by Broderick Chow, Eero Laine, and Claire Warden, 127-140. London and New York: Routledge.

Salmon, Catherine and Susan Clerc. 2005. "Ladies love wrestling, too": Female wrestling fans online. In steel chair to the head: The pleasure and pain of professional wrestling, 167-191. Durham, NC: Duke University Press.

Scherer, Jenna. 2017. Get in the ring: How 'GLOW' recreates the golden age of lady-wrestling TV.” Rolling Stone, June 23. https://www.rollingstone.com/tv/features/how-glow-recreates-thegolden-age-of-lady-wrestling-tv-w489354.

Schippers, Mimi. 2016. Beyond monogamy: Polyamory and the future of polyqueer sexualities. New York: New York University Press.

Smith, R. Tyson. 2008. Passion work: The joint production of emotional labor in professional wrestling. Social psychology quarterly 71, no. 2 (June): 157-176.

Solomon, Alisa. 2002. Great sparkles of lust: Homophobia and the great antitheatrical tradition. In The queerest art: essays on lesbian and gay theatre, edited by Alisa Solomon and Framji Minwalla, 9--20. New York: New York University Press. 
Guinea, Ximena Rojo de la Vega. 2018. Wrestling with masculinity: Exóticos in lucha libre. In Identity in professional wrestling: Essays on nationality, race, and gender, 109-119. Jefferson, NC: McFarland \& Company.

VanArendonk, Kathryn. 2019. Theorizing the Television Episode. Narrative 27, no. 1: 65-82.

Warden, Claire. 2018. "Might all be a work": Professional wrestling at Butlins holiday camps. The journal of popular sculture 51, no. 4 (August): 863-877.

Warden, Claire, Broderick Chow, and Eero Laine. 2018. Working loose: A response to 'Donald Trump shoots the match' by Sharon Mazer. TDR: The drama review 62, no. 2 (T238): 201-215.

Wood, Rachel and Ben Litherland. 2018. Critical feminist hope: The encounter of neoliberalism and popular feminism in WWE 24: Women's Evolution. Feminist media studies 18, no. 5: 905922. 